\title{
A study of vertebral geometry before and after conservative treatment in thoracic Scheuermann's disease AG Aulisa*1, V Guzzanti ${ }^{1}, \mathrm{C}$ Perisano $^{2}$, G Mastantuoni ${ }^{1}$ and L Aulisa ${ }^{2}$
}

\author{
Address: ${ }^{1}$ Orthopaedics and Traumatology Department Bambino Gesù Children's Hospital, Catholic University, P.zza s. Onofrio 4, 00165 Rome, \\ Italy and 2 Rome Institute of Scientific Research Orthopaedics and Traumatology Department, Catholic University, P.zza s. Onofrio 4, 00165 Rome, \\ Italy \\ Email: AG Aulisa* - agaulisa@tiscali.it \\ ${ }^{*}$ Corresponding author
}

from 6th International Conference on Conservative Management of Spinal Deformities Lyon, France. 21-23 May 2009

Published: I4 December 2009

Scoliosis 2009, 4(Suppl 2):OI9 doi:I0.II86/I748-7I6I-4-S2-OI9

This abstract is available from: http://www.scoliosisjournal.com/content/4/S2/OI9

(C) 2009 Aulisa et al; licensee BioMed Central Ltd.

\section{Background}

The study of the vertebral changes in Scheuermann's disease during conservative treatment is generally based upon the magnitude of the curve according to the Cobb method and the magnitude of the vertebral deformation in the sagittal plane. In the present study, an X-ray analysis of vertebral changes before and after bracing has been performed to assess whether additional radiographic parameters may aid in assessing the impact of the disease and the response to conservative treatment.

\section{Methods}

There were 16 patients with thoracic Scheuermann's disease undergoing treatment with an anti-gravity brace. Mean age at the onset of treatment was 13 years and patients had a mean curve value of $54.4^{\circ}$ kyphosis at the beginning of treatment. The following parameters were analyzed on a standard LL X-ray film taken before and at the end of treatment: cuneization angle (ALFA), anterior wall tilt (AANT), and posterior wall tilt (APOS). Each value was determined by two independent observers. Vertebrae were subdivided into three sectors: apical vertebrae (sector 4), those above the apical vertebra (sector 3), those below the apical vertebra (sector 5) and the marginal vertebrae (sector 2 and sector 6 ). The L1 vertebra was used as control (sector 1). Variations in each value were analyzed by means of the t-test for paired data. Significance was set at $\mathrm{P}<0.05$.

\section{Results}

For the hyperkyphotic curve: Parameters in all the kyphotic vertebrae show a significant reduction in the wedging angle ALFA $(\mathrm{P}<0.01)$ and in the posterior wall inclination APOS $(\mathrm{P}<0.0002)$. There was no significant variation in the anterior wall inclination. In sector 2: the posterior wall inclination decreased by about $50 \%$ in value $(\mathrm{P}<0.02)$. In sector 3 : the variation in values was not significant. In sector 4: at the apex vertebra level, body wedging decreased by $50 \%$ after treatment $(P<0.004)$. In sector 5: the posterior wall inclination decreased $(\mathrm{P}<$ $0.009)$. In sector 6 : the posterior wall inclination recorded a significant decrease of about $2^{\circ}(\mathrm{P}<0.001)$.

\section{Conclusion}

The analysis of results shows that additional parameters, particularly the anterior and posterior wall tilt that express the magnitude of trapezoidal deformation, may account for the response of vertebral geometry to conservative treatment in thoracic Scheuermann's kyphosis. Radiographic assessment of treatment outcome should therefore encompass both the traditional measures of curve and cuneization magnitude and the anterior and posterior vertebral wall tilt changes. 